\title{
Breast Cancer Patients Resistant to Endocrine Therapy Show Decreased Number of Cytotoxic Supressor Cells and Enhanced Production of Neoangiogenetic and Immunosupressive Factors
}

\author{
Eva Závadová, Michal Vočka, Bohuslav Konopásek, Terezie Fučíkova and Luboš Petruželka* \\ Department of Oncology, General Teaching Hospital and 1st Faculty of Medicine Charle's University, U Nemocnice 2, Prague 2, 12808 Czech Republic
}

\begin{abstract}
Background: Endocrine therapy is an essential modality in patients with hormone receptor positive breast cancer. Even with high therapeutic efficacy of first-line hormonal treatment, most patients with metastatic breast cancer will develop resistance. It appeals, that a factor contributing to the resistance may be a transforming factorbeta (TGF-beta). It is highly immunosuppressive factor that inhibits the natural and specific immunity against tumors and stimulates vascular endotelial growth factor (VEGF). The purpose of the study was to monitor immune responses in patients with hormone receptor positive breast cancer, particularly the examination of cellular (CD4, CD8) as well as humoral immunity, as well as TGF beta and VEGF production.
\end{abstract}

Materials and Methods: Patients included into the research project were implemented routine cancer teratment with hormonal therapy. Basic parameters (histological type and grade, the degree of expression of ER and PR, HER2, and the proliferative marker) were established. Patients were evaluated by a cancer clinical immunologist to exclude immune disorders, allergic or autoimmune origin. 12 healthy age matched persons served as control group.TGF beta, VEGF were mesured by ELISA and antitumor cellular immunity (CD4, CD8, antigen presenting cells) was measured by flow cytometry.

Results: In patients with resistance to endocrine therapy mainly depression in cellular immunity was found, CD 8 , cytotoxic T lymphocytes were significantly $[p<0.05]$ decreased. Immunglobuline plasma level was decreased as well (mainly lgG4 subtype [p<0.05]). Most patients have shown clinical symptoms of immunodeficiency (frequent infections of respiratory or urinary tract, herpetic infections). TGF beta as well as VEGF plasma level were significantly increased as compared with healthy person.

Conclusion: Correlation of these factors with resistance to endocrine therapy could help in the future with the prediction of therapy response and contribute to the selection of targeted therapy in breast cancer patients. Dedication: This project was supported by govermental grant IGA NT11168-3/2010.

Keywords: VEGF; TGF beta cellular immunity; Breast cancer; Hormonal therapy

\section{Introduction}

Breast cancer is one of the most common malignant diseases and the incidence in the developed countries still increases. Transformation of the epitelial cell of mammary gland into malignant cells is steroidal hormones dependent. Therefore the relative risk of breast cancer development depends on serum estrogen levels. Hormonal therapy is basic treatment in the patients with hormonal dependent breast cancer. The mechanisms of action of endocrine therapy are decrease of plasma estrogen concentrations, competitive inhibition and ER deregulation. Although more than $2 / 3$ of treated patients respond to the hormonal therapy, most of metastatic breast cancer patients develop antiestrogen resistence. To find out the reasons of the hormonal resistence is therefore priority in the cancer research. It was shown, that besides activated HER pathway, Transforming growth factor - beta1, (TGFbeta ) play an important role in the endocrine resistance and that TGF beta may influence hormonal receptors [1,2]. Additionally, TGF beta is neoangiogenetic and potent immunosupressive factor, reducing cellular anti-tumor imunity [3] (inhibition of antigen-presenting cells, NK cells, stimulation of $\mathrm{T}$ regulatory cells. Therefore TGFbeta1 is sugested to play the role as a resistence predictive marker [4]. More and more data are evolving in preclinical models suggesting that ovarian steroids cause cyclical changes, which have an impact on angiogenesis, and that estrogen modulates angiogenesis, in part, through the effects on VEGF. (Vascular endotelial growth factor, VEGF) [5]. VEGF is multi-functional glycoprotein acting as specific mitogen for endotelial cells and increasing vascular premeability as well. High VEGF levels were described in various human cancer types (breast cancer, endometrial cancer, ovarian cancer). Correlation of VEGF levels with the therapy response, disease stage and bad prognosis are currently discussed - VEGF is a neoangiogentetic factor increasing tumor neovascularisation and metastazing [6]. Defect of immune response correlate with bad prognosis and this is the reason why the recent cancer research focus on exact monitoring of cancer patients immunsystem and possibilities of immune system modulation [79]. Aim of the study was to seek new predictive markers of therapy

*Corresponding author: Prof. Luboš Petruželka MD, PhD, Department of Oncology, General Teaching Hospital and 1st Faculty of Medicine Charle's University, U Nemocnice 2, Prague 2, 12808 Czech Republic, Tel: +420 224962 219; Fax: +420 224921 716; E-mail: lubos.petruzelka@seznam.cz

Received November 16, 2011; Accepted December 15, 2011; Published December 17, 2011

Citation: Závadová E, Vočka M, Konopásek B, Fučíkova T, Petruželka L (2011) Breast Cancer Patients Resistant to Endocrine Therapy Show Decreased Numbe of Cytotoxic Supressor Cells and Enhanced Production of Neoangiogenetic and Immunosupressive Factors. J Cancer Sci Ther S2. doi:10.4172/1948-5956.S2-005

Copyright: (c) 2011 Závadová E, et al. This is an open-access article distributed under the terms of the Creative Commons Attribution License, which permits unrestricted use, distribution, and reproduction in any medium, provided the original author and source are credited. 
Citation: Závadová E, Vočka M, Konopásek B, Fučíkova T, Petruželka L (2011) Breast Cancer Patients Resistant to Endocrine Therapy Show Decreased Number of Cytotoxic Supressor Cells and Enhanced Production of Neoangiogenetic and Immunosupressive Factors. J Cancer Sci Ther S2. doi:10.4172/1948-5956.S2-005

Page 2 of 4

response in breast cancer patients, in particular immunity response by monitoring TGF-beta1 and VEGF plasma levels as well as the cellular immunity response and to find out, wheather the above mentioned parameters (TGF beta, VEGF levels and cellular antitumor immunity) correlate with disease prognosis and with the resistence to hormonal therapy. There are, besides HER-2 expression, no defined biomarkers correlating with antiestrogen therapy resistence. In this aspect, the role of VEGF and TGF betal is currently discussed. Tamoxifen treatment stimulates TGF beta production resulting into immunosupression and antiestrogen therapy failure. Correlation of high TGF or VEGF levels with resistence may therefore serve as a predictive factor.

\section{Materials and Methods}

15 adult postmenopausal women with histologically confirmed primary invasive breast carcinoma were included into the study. All patients were after surgery, primarily after ablation with axillary exenteration in 11 cases and after segmentectomia with axillary exenteration in 4 cases. Primary tumors were mainly in T1 stadium (1T1a, 2 T1b and 8 T1c), 2 were in T2, 1 in T3 and 1 in T4. Regional lymphatic nodes were without metastatic dissease (N0) in 7 cases, N1 in 6 cases, N2a once and in one case we do not have information about nodal status. All patient were without distant metastasis. So seven patients were in stage IA, 3 IIA, 3 in IIB, 1 in IIIA and 1 in IIIB. In point of histological view it was mainly invasive ductal carcinoma (13 women from which 2 with lobular component), 1 were invasive lobular carcinoma and 1 was combination of lobular and ductal type. All tumors were hormonal dependent, estrogene receptors were present in all of them except one was positive (this one histological examination was done in UK and we know only that ER was positive, but we have no histology), progesterone receptor were positive in 12 tumors. Her-2/ neu FISH was positive in only one case. All patient had got tamoxifen as a first line of hormonal therapy, median of using was 55.7 months (14140 months), before the relaps was found. In second line chemotherapy was given to one patient, 6 patients got anastrazol, 2 exemestan and 5 letrozol. After progresion of 4 pacient three of them got fulvestrant and one got anastrazol. Basic cancer parameters (histology type, expression of ER and PgR, expression of Her-2/neu and Ki-67) were determined in all cases before starting of hormonal therapy. The previous treatment including detailed hormonal anamnesis was also scrutinized (Table 1). All patients were examined by clinical immunologist in order to exclude defects of immune response due to autoimmunity or allergy.12 age matched non-diseased humans served as control group. We determined production of cytokines TGF beta and VEGF and cellular immune response (CD4+ and CD8+ lymphocytes, B-lymphocytes, NK cells,) in women with breast cancer as well as in the control group. Fluorescence activated cell sorter using monoclonal antibodies (Becton Dickinson) was used for cell identifications. Plasma TGF and VEGF level was determined by ELISA using monoclonal antiVEGF antibodies (R\&D Systems Inc., Minneapolis, MN) according to manufacturer instructions. Comparision of TGF or VEGF levels in the pactients with the resistence to hormonal therapy and control group was determined (Mann Whitney U test)

\section{Results}

In the group of 15 patients with hormonal resistant breast cancer plasma levels of TGF-beta were significatly $[\mathrm{p}<0.05]$ increased :mean $16126 \mathrm{pg} / \mathrm{ml}$, SEM 2440) as compared with control group: mean 6995 $\mathrm{pg} / \mathrm{ml}$, SEM 1462.VEGF was significatly $[\mathrm{p}<0.05]$ increased as well :mean $123,1 \mathrm{pg} / \mathrm{ml}$ SEM $17,87 \mathrm{pg} / \mathrm{ml}$ ) as compared with control group: mean 21,71, SEM 5,875 (Figure 1,2).

We observed significant decrease $[\mathrm{p}<0.05]$ in cell mediated antitumor immunity, mainly lower level of CD8+ T lymphocytes (cytotoxic effector cells, mean 24,47\%, SEM 2,028) as compared with control group mean $35,33 \%$, SEM 2,603 (Figure 3). |The percentual and absolute number of B lymfocytes (CD19) was also decreased [p

\begin{tabular}{|c|c|c|c|c|}
\hline & TNM & stage & description & grade \\
\hline patient 1 & pT1cNo(2/0+)M0 & IA & $\begin{array}{l}\text { combination of invasive ductal } \\
\text { and lobular carcinoma }\end{array}$ & - \\
\hline patient 2 & pT1cNo(2/0+)MX & IA & invasive ductal carcinoma & - \\
\hline patient 3 & pT1aN1(4/3+)MX & IIA & invasive ductal carcinoma & - \\
\hline patient 4 & pT2N1(5/1+)MX & IIB & invasive ductal carcinoma & - \\
\hline patient 5 & pT3N0(5/0+)MX & IIB & invasive ductal carcinoma & G2-3 \\
\hline patient 6 & pT1bN0(6/0+)MX & IA & invasive ductal carcinoma & G1 \\
\hline patient 7 & pT1cN2a(19/4+)MX & IIIA & invasive ductal carcinoma & G2 \\
\hline patient 8 & pT1cNo(0/0+)MX & IA & $\begin{array}{l}\text { invasive lobular carcinoma } \\
\text { with small LCIS component }\end{array}$ & - \\
\hline patient 9 & pT1cN1(8/1+)MX & IIA & invasive ductal carcinoma & - \\
\hline patient 10 & pT1bN0(5/0+)MX & IA & $\begin{array}{l}\text { invasive ductal carcinoma } \\
\text { with lobular component }\end{array}$ & G1-2 \\
\hline patient 11 & pT4N1(3/3+)MX & IIIB & invasive ductal carcinoma & - \\
\hline patient 12 & pT2N1(3/3+)MX & IIB & invazive lobular carcinoma & - \\
\hline patient 13 & pT1cNo(5/0+)MX & IA & invasive ductal carcinoma & G2-3 \\
\hline patient 14 & $\mathrm{pT} 1 \mathrm{cNX}(0 / 0+) \mathrm{MX}$ & IA & invasive ductal carcinoma & G2 \\
\hline patient 15 & pT1cN1(3/1+)MX & IIA & $\begin{array}{l}\text { invasive ductal carcinoma } \\
\text { with lobular component }\end{array}$ & G2 \\
\hline
\end{tabular}

Table 1: Patients characteristics. 
$<0.05$ ], mean 10,13\%, SEM 1,291) as compared with control group of healthy individuals:mean 13,67\%, SEM 0,9189 (Figure 4). Level of antigen presenting cells (HLA-DR positive) was not alternate. Percentage of NK cells was under normal level in 9 cases. In humoral immunity, we observed significantly $[\mathrm{p}<0.05]$ decreased level of immunoglobuline in 11 from 15 cases, mainly in class IgG4 (7 from 15). mean $0,5150 \mathrm{U} / \mathrm{ml}$, SEM 0,1425 ) as compared with control group of healthy individuals:mean $1,010 \mathrm{U} / \mathrm{ml}$, SEM 0,1693.In 8 from 15 cases there were symptoms of immunodeficiency - repeated infections

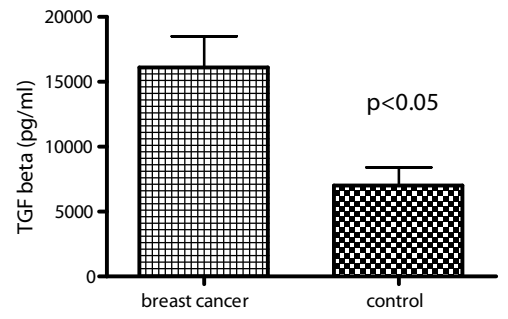

Figure 1: Levels of plasmatic TGF beta breast cancer vs. control (healthy individuals).

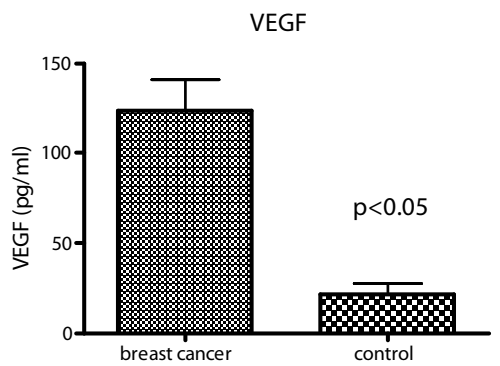

Figure 2: Levels of plasmatic VEGF breast cancer vs. control (healthy individuals).

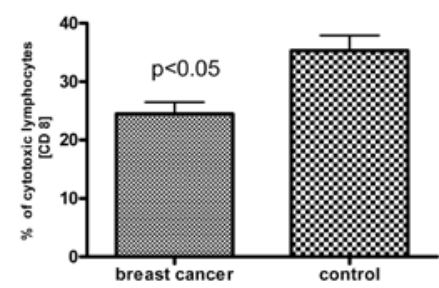

Figure 3: There was a significant decrease of CD 8 (cytotoxic lymphocytes) in periferal blood of breast cancer patient resistent to hormonal therapy as compared to healthy person $[p<0.05]$.

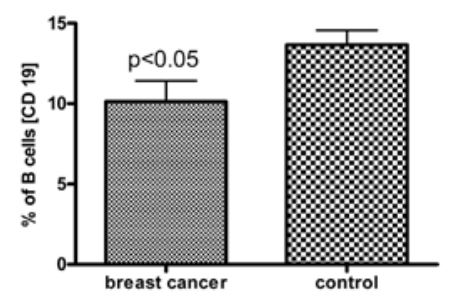

Figure 4: There was a significant decrease of B cells in periferal blood of breast cancer patient resistent to hormonal therapy as compared to healthy person $\mathrm{p}<0.05]$.

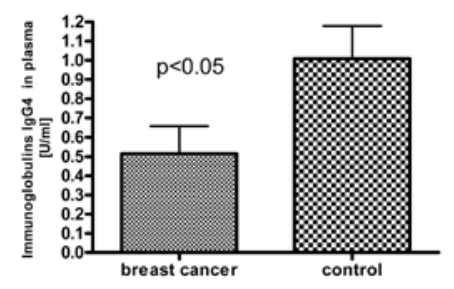

Figure 5: There was a significant decrease of Immunoglobulins level [lgG4] in periferal blood of breast cancer patient resistent to hormonal therapy as compared to healthy person $[p<0.05]$.

of upper airways, infections of urinary tract and herpetic infections (Figure 5). In 8 cases there were found serological signs of active and chronic chlamydial infections. Zoster virus was found in 2 cases and anamnestic antibodies against Borrrelia was elevated in 4 cases.

\section{Discussion}

Even trough rising use of selective aromatase inhibitors, the antiestrogen therapy is still very important. Estrogens modes of actions are transmitted into the cell trough nuclear receptors (ER/PR). After activation, those receptors serve (together with other regulatory molecules) as a transcription regulators. Increased expression of hormonal receptors is the important condition of the hormonal therapy effectivenes. Antiestrogens are the base of hormonal treatment in the premenopausal as well as postmenopausal patiens with hormon-dependent breast cancer and those patients with metastatic disease receive hormonal therapy in the neoadjuvant as well as in the adjuvant indication. However, the effectivity of hormonal treatment is mostly time-limited since most patients develop resistence to this treatment. Hormonal resistence could be primar, but it is mostly developing during the treatment after documented therapy response. Molecular prediction of resistence is the possibility to optimize therapy strategy. Developing resistence in patients with hormonal dependent carcinomas is complex process, which interfere with intracelular signal transduction on the molecular level.

Besides HER there are no known predicitive markers of resistence to antiestrogen therapy. The role of transforming growth factor beta1 (TGF-beta1), influencing hormonal receptors and being potent immunosupressive factor reducing cellular anti-tumor immunity is currently discussed [10]. Estrogenes ifluent angiogenetic processes resulting into metastasis paritculary trough Vascular endotelial growth factor (VEGF). Therefore VEGF as well as TGF-beta1 are sugested to play the role as a predictive marker of the disease progression. Aim of our study was to find out, wheather the above mentioned parameters (TGF-beta1 and VEGF plasma levels as well as the cellular immunity) correlate with with the hormonal resistence development. Our results suggest that overproduction of neoangiogenetic and immunosupressive factors are enhanced in patients resistant to endocrine therapy. Correlation of these factors with resistance to hormonal therapy and immune status could refine the prediction of resistance and to contribute to any targeted imunointervention therapy and targeted selection of cancer treatment. This finding could help in the future to seek new risk predictive markers in breast cancer patients. More studies are necessary in order to show wheather those factors can be used for adjusting the individual therapy in patients with hormonally dependent breast cancer. Detailed immunologic exam, especialy 
Citation: Závadová E, Vočka M, Konopásek B, Fučíkova T, Petruželka L (2011) Breast Cancer Patients Resistant to Endocrine Therapy Show Decreased Number of Cytotoxic Supressor Cells and Enhanced Production of Neoangiogenetic and Immunosupressive Factors. J Cancer Sci Ther S2. doi:10.4172/1948-5956.S2-005

Page 4 of 4

focused on TGF-beta and VEGF level determination could identify risk group of patients with early or late resistence to hormonal therapy. Patients having elevated TGF-beta or VEGF levels can receive intensive dispensary care or possibly chemoprevention will be recommended. In case of confirmed TGF-beta or VEGF elevation and alteration of cellular immunity in a bigger study, another prognostic-predictive marker influencing therapy protocol could be obtained. TGF-beta and VEGF determination could serve as an additional marker monitoring clinical status during endocrine therapy. It would be also important in the future to evaluate disease free time and overal survival time. In case of correlation of high TGF-beta or VEGF plasma level with overall survival time additive immunotherapy could be recommended (supression of VEGF or TGF-beta overproduction with monoclonal antibodies, stimulation of antigen presentaion, NK cells an CD8 cells support). Clear statement about the role of VEGF and TGF-beta and possibly correlation with resistance to hormonal therapy and impaired status of cellular imunity (mostly inhibition of CD8 effector lymphocytes killing the tumor cells) could not only support prediction of resistence and to help to choose appropriate therapy, but also help to decide other important questions: wheather to choose or not more aggressive therapy. Such correlation can even show new possibilities regarding immunotherapy (stimulation of anti tumor immunity, stimulation of antigen presenting cells and downregulation of TGFbeta and VEGF overproduction combined with hormonal therapy).

\section{Acknowledgement}

Dedication: This project was supported by govermental grant IGA NT111683/2010.

\section{References}

1. Turner S, Sherratt J, Cameron D (2004) Tamoxifen treatment failure in cancer and the nonlinear dynamics of TGFbeta. J Theor Biol 229: 101-111.

2. Desruisseau S, Palmari J, Giusti C, Romain S, Martin PM, et al. (2006) Determination of TGFbeta1 protein level in human primary breast cancers and its relationship with survival. $\mathrm{Br} \mathrm{J}$ Cancer 94: 239-246.

3. Brown RD, Pope B, Murray A, Esdale W, Sze DM, et al. (2001) Dendritic cells from patients with myeloma are numerically normal but functionally defective as they fail to up-regulate CD80 (B7-1) expression after huCD40LT stimulation because of inhibition by transforming growth factor-beta1 and interleukin-10. Blood 98: 2992-2998.

4. Todorovic-Rakovic N (2005) TGF-beta 1 could be a missing link in the interplay between ER and HER-2 in breast cancer. Med Hypotheses 65: 546-551.

5. Zhang XH, Huang DP, Guo GL, Chen GR, Zhang HX, et al. (2008) Coexpression of VEGF-C and COX-2 and its association with lymphangiogenesis in human breast cancer. BMC Cancer 8: 4.

6. Delli Carpini J, Karam AK, Montgomery L (2010) Vascular endothelial growth factor and its relationship to the prognosis and treatment of breast, ovarian, and cervical cancer. Angiogenesis 13: 43-58.

7. Biswas S, Criswell TL, Wang SE, Arteaga CL (2006) Inhibition of transforming growth factor-beta signaling in human cancer: targeting a tumor suppressor network as a therapeutic strategy. Clin Cancer Res 12: 4142-4146.

8. Matsumura Y, Kobayashi T, Ichiyama K, Yoshida R, Hashimoto M, et al. (2007) Selective expansion of foxp3-positive regulatory $T$ cells and immunosuppression by suppressors of cytokine signaling 3-deficient dendritic cells. J Immunol 179 2170-2179.

9. Wright SE, Rewers-Felkins KA, Quinlin IS, Phillips CA, Townsend M, et al. (2010) Number of treatment cycles influences development of cytotoxic T cells in metastatic breast cancer patients - a phase I/II study. Immunol Invest 39 570-586.

10. Ghellal A, Li C, Hayes M, Byrne G, Bundred N, et al. (2000) Prognostic significance of TGF beta 1 and TGF beta 3 in human breast carcinoma Anticancer Res 20: 4413-4418. 